\title{
PERBANDINGAN AKURASI SOFTWARE RAPIDMINER DAN WEKA MENGGUNAKAN ALGORITMA K-NEAREST NEIGHBOR (K-NN)
}

\section{Devi Damayanti}

Universitas Pamulang (UNPAM) Tanggerang Selatan Banten, Indonesia

Email: dosen02390@unpam.ac.id

\begin{tabular}{l} 
INFO ARTIKEL \\
\hline Diterima \\
3 Juni 2021 \\
Direvisi \\
8 Juni 2021 \\
Disetujui \\
21 Juni 2021
\end{tabular}

Keywords:

prediction; data mining; k-nn; rapidminer; weka; accuracy

\begin{abstract}
One of the keys to a person's success in taking education is the period of study. Likewise, universities are required to provide quality education for students because students are assets for an educational institution so that it is necessary to pay attention to the graduation rate of their students so that they are on time. The research was conducted at Sahid University Jakarta, Faculty of Economics, Management Study Program. From the data obtained, it shows that many students do not graduate on time, which is 4 years or 8 semesters. The delay in graduating students can be caused by several factors, one of which is the disruption of the lecture process. There are many aspects that support the disruption of the lecture process, including the lack of student ability in the course, the lack of student attendance in the lecture process and various other aspects that cannot be measured. The purpose of this study is to compare the accuracy results produced by the two software, Rapidminer and WEKA using the K-NN algorithm with the fold cross validation method, processing previous data that will be used as predictions for graduates in the coming years. The attributes used are IPS 1 to IPS 8, IPK semester 2 to IPK semester 8 and compulsory subjects. Making eight data samples to be tested with different value limits based on the Regulation of the Minister of Education and Culture of the Republic of Indonesia Number 49 of 2014 concerning National Standards for Higher Education. The results showed that the WEKA software with the K-NN algorithm produced a higher accuracy value than Rapidminer, which was $78.25 \%$. So can be used as an alternative method to predict the punctuality of graduation at Sahid University, Jakarta.
\end{abstract}

\section{ABSTRAK}

Salah satu kunci keberhasilan seseorang dalam

\begin{tabular}{|c|c|c|c|c|}
\hline How to cite: & Damayanti, Devi (2021). Perbandingan & Akurasi Software $\mathrm{R}$ & Rapidminer dan & Weka Menggunakan \\
\hline & $\begin{array}{l}\text { Algoritma K-Nearest Neighbor } \\
\text { https://doi.org/10.46799/jsa.v2i6.247 }\end{array}$ & (K-NN). Jurnal & Syntax & Admiration \\
\hline E-ISSN: & $2722-5356$ & & & \\
\hline Published by: & Ridwan Institute & & & \\
\hline
\end{tabular}




\begin{tabular}{|c|c|}
\hline $\begin{array}{l}\text { Kata Kunci: } \\
\text { prediksi; data mining; K- } \\
\text { NN; rapidminer; WEKA; } \\
\text { akurasi }\end{array}$ & $\begin{array}{l}\text { menempuh Pendidikan adalah masa studi. Sama hal nya } \\
\text { dengan perguruan tinggi dituntut untuk } \\
\text { menyelenggarakan Pendidikan yang berkualitas bagi } \\
\text { mahasiswa karena mahasiswa adalah aset bagi sebuah } \\
\text { institusi pendidikan sehingga perlu diperhatikan tingkat } \\
\text { kelulusan mahasiswanya agar tepat pada waktunya. } \\
\text { Penelitian dilaksanakan di Universitas Sahid Jakarta } \\
\text { Fakultas Ekonomi Prodi Manajemen. Dari data yang } \\
\text { didapatkan menunjukkan bahwa banyak mahasiswa yang } \\
\text { lulus tidak tepat pada waktu yang telah ditentukan yaitu } 4 \\
\text { tahun atau } 8 \text { semester. Keterlambatan waktu lulus } \\
\text { mahasiswa dapat disebabkan oleh beberapa faktor, salah } \\
\text { satunya proses perkuliahan yang terganggu. Banyak } \\
\text { aspek yang mendukung terganggunya proses perkuliahan } \\
\text { diantaranya kurangnya kemampuan mahasiswa terhadap } \\
\text { mata kuliah, kurangnya kehadiran mahasiswa dalam } \\
\text { mengikuti proses perkuliahan dan berbagai aspek lainnya } \\
\text { yang tidak dapat diukur. Tujuan Penelitian ini adalah } \\
\text { membandingkan hasil akurasi yang dihasilkan oleh kedua } \\
\text { software yaitu Rapidminer dan WEKA menggunakan } \\
\text { algoritma K-NN dengan metode fold cross validation, } \\
\text { mengolah data sebelumnya yang akan dijadikan prediksi } \\
\text { untuk lulusan tahun-tahun yang akan datang. Atribut } \\
\text { yang digunakan adalah IPS } 1 \text { sampai IPS } 8 \text {, IPK semester } \\
2 \text { sampai IPK semester } 8 \text { dan mata kuliah wajib. } \\
\text { Membuat delapan sampling data untuk diujikan dengan } \\
\text { batasan nilai yang berbeda-beda berpacu pada Peraturan } \\
\text { Menteri Pendidikan dan Kebudayaan Republik Indonesia } \\
\text { Nomor } 49 \text { Tahun 2014 Tentang Standar Nasional } \\
\text { Pendidikan Tinggi. Hasil penelitian menunjukan bahwa } \\
\text { software WEKA dengan algoritma K-NN menghasilkan } \\
\text { nilai akurasi yang lebih tinggi dibandingkan dengan } \\
\text { Rapidminer yaitu sebesar } 78,25 \% \text {. Sehingga dapat } \\
\text { digunakan menjadi alternatif metode untuk memprediksi } \\
\text { ketepatan waktu kelulusan di Universitas Sahid Jakarta. }\end{array}$ \\
\hline
\end{tabular}

\section{Pendahuluan}

Salah satu hal yang dapat dijadikan sebagai ukuran keberhasilan seseorang dalam menempuh pendidikan adalah masa studi. Masa studi merupakan masa untuk menyelesaikan beban studi dalam mengikuti proses pendidikan pada program studinya. Sama halnya dengan perguruan tinggi dituntut untuk menyelenggarakan pendidikan yang berkualitas bagi mahasiswa sehingga menghasilkan sumber daya manusia yang 
berilmu, cakap, kreatif dan bersaing. Dalam sistem pendidikan mahasiswa adalah aset penting bagi sebuah institusi pendidikan dan untuk itu perlu diperhatikan tingkat kelulusan mahasiswa tepat pada waktunya.

Persentase naik turunnya kemampuan mahasiswa untuk menyelesaikan studi tepat waktu merupakan salah satu elemen penilaian akreditasi universitas (Tinggi 2008). Sehingga perlu adanya pemantauan dan evaluasi terhadap kecenderungan mahasiswa lulus tepat waktu atau tidak.

Penelitian ini akan dilakukan pada salah satu program studi yang ada di Fakultas Ekonomi (S1) yaitu Program Studi Manajemen. Berdasarkan data yang diperoleh dari Wakil Direktur Administrasi dan Akademik Universitas Sahid Jakarta mulai dari tahun 2011 sampai dengan tahun 2015. Pada tahun 2011 total jumlah kelulusan mahasiswa adalah 96 mahasiswa dengan waktu kelulusan rata-rata 4,9 tahun, tahun 2012 jumlah kelulusan sebanyak 68 mahasiswa dengan waktu kelulusan rata-rata 4,64 tahun, tahun 2013 jumlah kelulusan mahasiswa sebanyak 96 mahasiswa dengan waktu kelulusan rata-rata 4,62 tahun, tahun 2014 jumlah kelulusan mahasiswa sebanyak 94 mahasiswa dengan waktu kelulusan rata-rata 4,72 tahun dan tahun 2015 jumlah kelulusan mahasiswa sebanyak 119 mahasiswa dengan waktu kelulusan rata-rata 4,67 tahun. Dengan rata-rata kelulusan per tahun dalam lima tahun terakhir adalah 95 mahasiswa dalam waktu 4,71 tahun.

Dari data tersebut menunjukkan bahwa banyak mahasiswa yang lulus tidak tepat pada waktu yang telah ditentukan yaitu 4 tahun atau 8 semester. Keterlambatan waktu lulus mahasiswa dapat disebabkan oleh beberapa faktor, salah satunya proses perkuliahan yang terganggu. Banyak aspek yang mendukung terganggunya proses perkuliahan diantaranya kurangnya kemampuan mahasiswa terhadap mata kuliah, kurangnya kehadiran mahasiswa dalam mengikuti proses perkuliahan dan berbagai aspek lainnya yang tidak dapat diukur.

Data mining merupakan proses penemuan pola dalam data dengan cara menganalisa data yang sudah ada dalam database (Ngo 2011) sehingga ketepatan waktu kelulusan mahasiswa dapat diklasifikasikan menggunakan teknik data mining. Membandingkan hasil akurasi dari kedua tools data Mining Rapidminer dan WEKA yang masuk ke dalam Six Of The Best Open Source Data Mining Tools dari data yang didapatkan pada (Chertchom 2018) diharapkan informasi yang dihasilkan lebih detail dan akurat sehingga ke depannya dapat menjadi alternatif metode untuk memprediksi ketepatan waktu kelulusan di Universitas Sahid Jakarta.

Penelitian terdahulu terkait dengan penelitian mengenai prediksi ketepatan waktu kelulusan, algoritma serta software data mining yang sama diantaranya yaitu oleh (Mustafa and Simpen 2014) berjudul Perancangan Aplikasi Prediksi Kelulusan Tepat Waktu Bagi Mahasiswa Baru Dengan Teknik Data Mining (Studi Kasus: Data Akademik Mahasiswa Stmik Dipanegara Makassar) hasil penelitian akurasi algoritma K-Nearest Neighbor adalah 83,36\%. (Huda 2020) berjudul Perbandingan Akurasi $K$ Nearest Neighbor Dan Nä̈ve Bayes Untuk Algoritma Sistem Prediksi Nilai Akhir Mahasiswa hasil penelitiannya Algoritma terbaik adalah K-NN dengan K=15 dan nilai 
akurasinya adalah 95\%.(Kamagi and Hansun 2014) berjudul Implementasi Data Mining Dengan Algoritma C4.5 Untuk Memprediksi Tingkat Kelulusan Mahasiswa dengan hasil penelitian Tingkat akurasi aplikasi dari hasil prediksi adalah 87,5\%. (Nursalim and Himawan 2014) berjudul Klasifikasi Bidang Kerja Lulusan Menggunakan Algoritma K-Nearest Neighbor (KNN) dengan hasil penelitian Algoritma KNN memiliki kinerja terbaik untuk klasfikasi bidang kelulusan dengan nilai akurasi 83,33\% AUC 0,900. (Rohman 2015) berjudul Model Algoritma K-Nearest Neighbor (K-NN) Untuk Prediksi Kelulusan Mahasiswa dengan hasil penelitian Tingkat akurasi tertinggi pada klaster $\mathrm{k}=5$ yaitu $85,15 \%$. (Banjarsari, Budiman, and Farmadi 2016) berjudul Penerapan K-Optimal Pada Algoritma Knn Untuk Prediksi Kelulusan Tepat Waktu Mahasiswa Program Studi Ilmu Komputer Fmipa Unlam Berdasarkan Ip Sampai Dengan Semester 4 dengan hasil penelitian Tingkat akurasi tertinggi pada klaster $\mathrm{K}=5$ yaitu 80,00\%. (Mustakim and Oktaviani 2016) berjudul Algoritma K-Nearest Neighbor Classification Sebagai Sistem Prediksi Predikat Prestasi Mahasiswa dengan hasil penelitian Algoritma K-NN menghasilkan akurasi sebesar 82\%. (Srianto and Mulyanto 2016) berjudul Perbandingan K-Nearest Neighbor Dan Nä̈ve Bayes Untuk Klasifikasi Tanah Layak Pohon Jati dengan hasil penelitian K-NN lebih baik dibandingkan dengan Nä̈ve Bayes dengan akurasi 96,66\% dan 82,63\%. algoritma K-Nearest Neighbor Classification sebagai sistem prediksi predikat prestasi mahasiswa oleh (Mustakim and Oktaviani 2016) menghasilkan akurasi K-NN sebesar $82 \%$. Dengan hasil akurasi yang di dapat dari penelitian-penelitian sebelumnya peneliti tertarik untuk menggunakan algoritma K-NN yang akan dihitung ke dalam dua tools data mining yaitu Rapidminer dan WEKA dengan tujuan untuk mengetahui diantara kedua tools tersebut yang lebih tinggi tingkat akurasinya

(Muin 2016) berjudul Metode Nä̈ve Bayes Untuk Prediksi Kelulusan (Studi Kasus: Data Mahasiswa Baru Perguruan Tinggi) dengan hasil penelitian Tingkat akurasi Nä̈ve Bayes mencapai 94\%. Dari beberapa penelitian terdahulu akhirnya peneliti memutuskan melakukan penelitian membandingkan software Rapidminer dan WEKA dengan menggunakan satu algoritma klasifikasi yaitu algoritma K-NN yang menurut peneliti adalah suatu kebaruan dari penelitian karena peneliti belum menemukan dengan metode yang sama. Selain kebaruan penelitian, tujuan dilakukannya penelitian ini adalah agar mendapatkan nilai akurasi yang paling baik diantara kedua software data mining tersebut sehingga hasilnya nanti akan dapat menjadi alternatif metode bagi Universitas Sahid Jakarta untuk memprediksi kelulusan mahasiswanya di tahun - tahun berikutnya.

\section{Metode Penelitian}

Data yang digunakan untuk penelitian adalah data mahasiswa Fakultas Ekonomi program studi Manajemen (S1) dalam waktu kelulusan mulai tahun 2011. Dari jumlah mahasiswa yang lulus tepat waktu dan tidak tepat waktu dalam 5 tahun sampai dengan tahun 2015 berjumlah 149 data mahasiswa. Dari data awal yang dikumpulkan sebanyak 473 data mahasiswa yang kemudian melalui 6 tahapan teknik analisis yaitu domain 
understanding, selection and addition, data cleaning, transformation, evaluation and interpretation, dan discover knowledge sehingga menghasilkan data lengkap hanya berjumlah 149 data mahasiswa.

Tabel 1

Pemilihan Atribute

\begin{tabular}{cccc}
\hline No. & Atribut & Keterangan & Detail \\
\hline $\mathbf{1}$ & IPS & $\begin{array}{c}\text { Indeks Prestasi } \\
\text { Sementara }\end{array}$ & $\begin{array}{c}\text { Indeks Prestasi Sementara } \\
\text { Semester 1 sampai dengan } \\
\text { Semester 8 }\end{array}$ \\
\hline $\mathbf{2}$ & IPK & $\begin{array}{c}\text { Indeks Prestasi } \\
\text { Kumulatif }\end{array}$ & $\begin{array}{c}\text { Indeks Prestasi Kumulatif } \\
\text { Semester 2 sampai dengan } \\
\text { Semester 8 }\end{array}$ \\
\hline $\mathbf{3}$ & MK & Mata Kuliah & Mata Kuliah Wajib \\
& & & $\begin{array}{c}\text { (Pengantar Manajemen, } \\
\text { Manajemen Operasi, } \\
\text { Manajemen SDM) }\end{array}$ \\
\hline $\mathbf{4}$ & KT & Status Keterangan & Tepat Waktu dan Tidak \\
& & Lulus & Tepat Waktu \\
\hline
\end{tabular}

Pemilihan atribut yang terdiri dari kumpulan nilai disebut dengan Indeks Prestasi per semester dan Indeks Prestasi Kumulatif serta nilai mata kuliah wajib ini diharapkan dapat meningkatkan nilai akurasi yang diperoleh dari perhitungan algoritma K-NN serta bertujuan untuk mengumpulkan nilai-nilai agar dapat dijadikan acuan prediksi kelulusan tepat waktu atau tidak tepat waktu.

Mencari tingkat akurasi yang paling baik, peneliti menggunakan 8 data sampling dengan masing-masing batasan nilai yang berbeda. Batasan-batasan nilai yang digunakan adalah sebagai berikut:

Tabel 2

Batasan Data Set untuk Pembuatan Sampling Pengujian Algoritma

\begin{tabular}{ccccc}
\hline Sampling & $\begin{array}{c}\text { Batasan Nilai Atribut } \\
\text { IPS / IPK }\end{array}$ & Predikat & $\begin{array}{c}\text { Batasan Nilai Atribut } \\
\text { Mata Kuliah Wajib }\end{array}$ & Predikat \\
\hline 1 & 2,00 & Cukup & 2 / C & Cukup \\
\hline 2 & 2,76 & Memuaskan & 2 / C & Cukup \\
\hline 3 & 3,01 & Sangat memuaskan & 2 / C & Cukup \\
\hline 4 & 3,50 & Pujian & 2 / C & Cukup \\
\hline 5 & 2,00 & Cukup & 3 / B & Baik \\
\hline 6 & 2,76 & Memuaskan & 3 / B & Baik \\
\hline 7 & 3,01 & Sangat memuaskan & 3 / B & Baik \\
\hline 8 & 3,50 & Pujian & $3 /$ B & Baik \\
\hline
\end{tabular}

Menguji pola klasifikasi pada penelitian ini adalah metode K-Fold Cross Validation. Dalam K-Fold Cross Validation, data dibagi menjadi k bagian, D1, D2, ... Dk, dan masing-masing D memiliki jumlah data yang sama. Kemudian dilakukan proses pengulangan sebanyak $\mathrm{K}$, dimana dalam setiap pengulangan ke-I, D akan dijadikan data testing, dan sisanya akan dijadikan data training. Sebagai contoh misalkan akan dilakukan metode cross validation dengan menggunakan 3-fold. Pertama pilih salah satu fold menjadi data testing, kemudian fold sisanya menjadi data training. 
Hal ini dilakukan berulang untuk semua kombinasi data training-testing. Sebagai ilustrasi, perhatikan gambar dibawah ini.

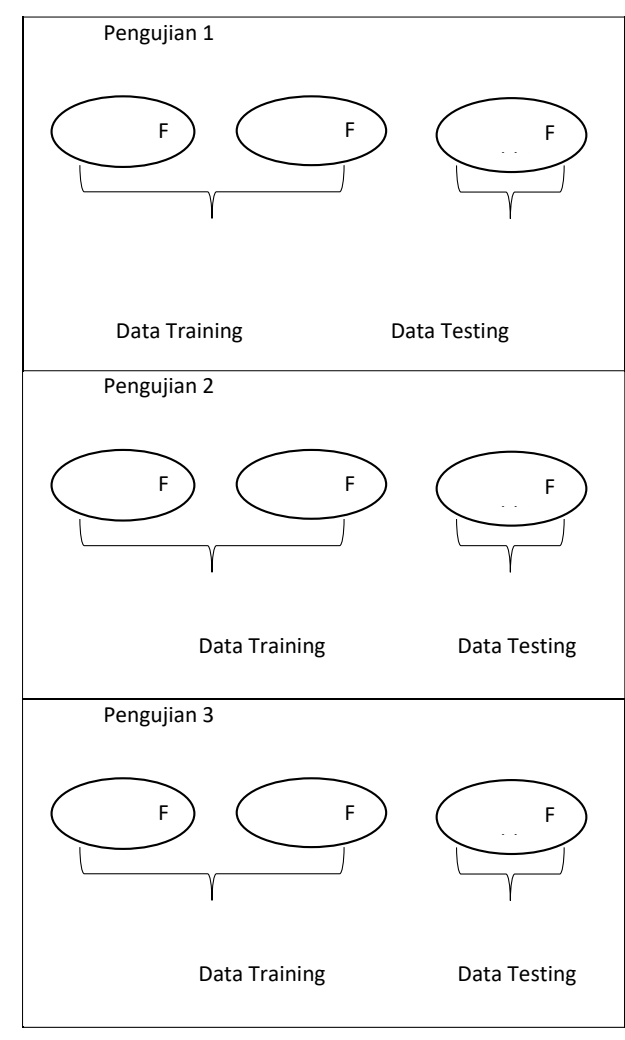

Gambar 1

Ilustrasi 3-Fold Cross Validation

Sistem dalam klasifikasi diharapkan mampu melakukan semua set data dengan benar, namun tidak dapat dipungkiri bahwa kesalahan pasti akan terjadi dalam proses pengklasifikasian. Untuk itu perlunya dilakukan pengukuran kinerja klasifikasi dengan matriks konfusi (confusion matrix). Matrik konfusi adalah tabel pencatat hasil kerja klasifikasi yang terdapat pada Rapidminer dan WEKA.

Setelah mendapatkan 8 data sampling, pengujian keakuratan dari suatu klasifikasi, dengan ketentuan memakai 3, 5, 10, 15 dan 20 fold cross validation yang diharapkan akan menemukan tingkat akurasi yang terbaik.

Pengujian algoritma K-NN menggunakan Rapidminer contoh menggunakan sampling data ke-1 dan metode pengujian 3 fold cross validation. 


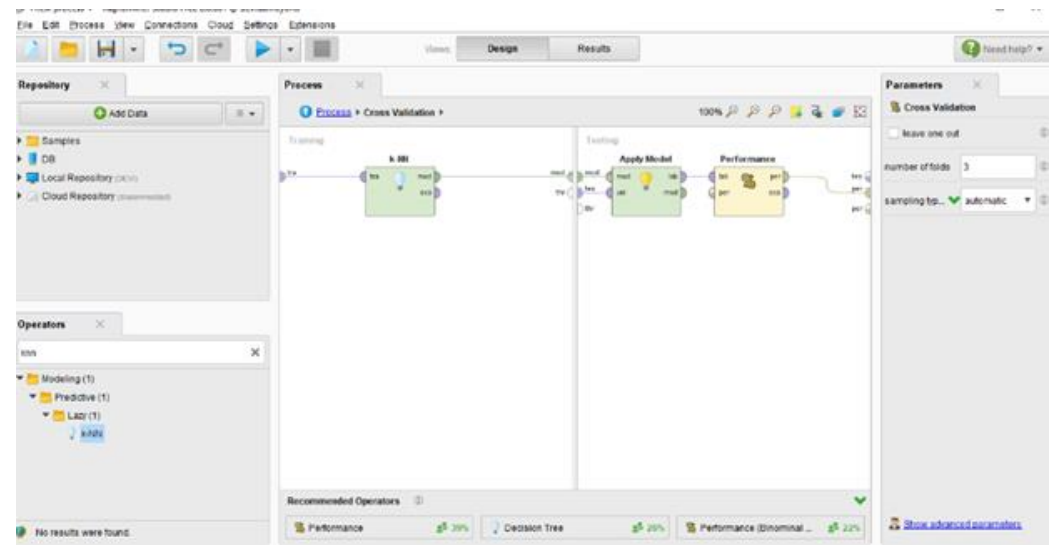

Gambar 2

Subproses Training dan Testing K-NN

ExampleSet yang sudah dilatih sebelumnya akan dibangun dengan metode K-NN. Apply model berfungsi mempelajari ExampleSet yang sudah dilatih sedangkan performance ini digunakan untuk evaluasi statistik dari kinerja klasifikasi dan memberikan daftar nilai kriteria dari kinerja klasifikasi tersebut.

Algoritma K-NN pada subproses training sedangkan apply model dan performance pada subproses testing, kemudian masing-masing dihubungkan ke port. Setelah itu mulai lah proses pengujian dengan menggunakan algoritma K-NN.

Hasil akurasi pengujian data sampling ke-1 dengan algoritma K-NN menggunakan 3 fold cross validation adalah sebagai berikut:

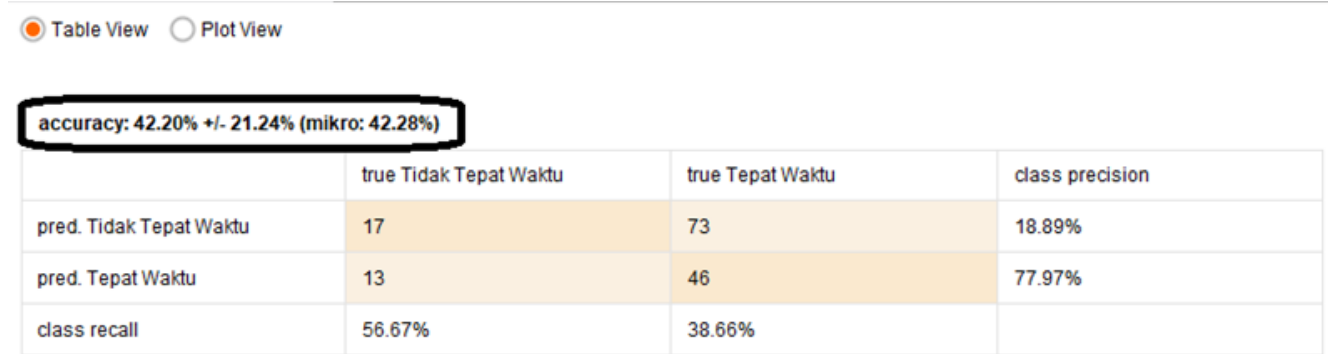

\section{Gambar 3}

\section{Hasil Akurasi Sampling ke-1 Algoritma K-NN menggunakan 3 Fold Cross Validation}

Hasil akurasi dengan perhitungan nilai confusion matrix terhadap algoritma K-NN menggunakan Rapidminer dengan 3 fold cross validation yang menghasilkan tingkat akurasi sebesar $42,28 \%$ adalah sebagai berikut:

Pred Tidak Tepat Waktu-true Tidak Tepat Waktu = jumlah data yang diprediksi Tidak Tepat Waktu dan kenyataannya Tidak Tepat Waktu (TP)

1. Pred Tepat Waktu - true Tepat Waktu = jumlah data yang diprediksi Tepat Waktu dan kenyataanya Tepat Waktu (TN)

2. Pred Tidak Tepat Waktu - true Tepat Waktu = jumlah data yang diprediksi Tidak Tepat Waktu tapi kenyataanya Tepat Waktu (FP) 
Perbandingan Akurasi Software Rapidminer dan Weka Menggunakan Algoritma $K$ Nearest Neighbor (K-NN)

3. Pred Tepat Waktu - true Tidak Tepat Waktu = jumlah data yang diprediksi Tepat Waktu tapi kenyataanya Tidak Tepat Waktu (FN)

$$
\begin{aligned}
\text { Accuracy } & =\frac{\mathrm{TP}+\mathrm{TN}}{\mathrm{TP}+\mathrm{TN}+\mathrm{FP}+\mathrm{FN}} \\
\text { Accuracy } & =\frac{17+46}{17+46+73+13} \\
\text { Accuracy } & =\frac{63}{149}=42,28 \%
\end{aligned}
$$

Hasil perhitungan dengan rumus akurasi, terlihat bahwa hasil yang didapat dengan hasil pada Rapidminer adalah sama.

Setelah dilakukan pengujian dengan menggunakan tool Rapidminer selanjutnya ke delapan sampling data tersebut akan kembali diuji dengan menggunakan tool WEKA. Pada pengujian algoritma K-NN menggunakan tool WEKA juga dilakukan dengan menggunakan cross-validation dengan 3, 5, 10, 15 dan 20 fold. Sebagai contoh akan menggunakan 3 fold, seperti pada gambar di bawah ini.

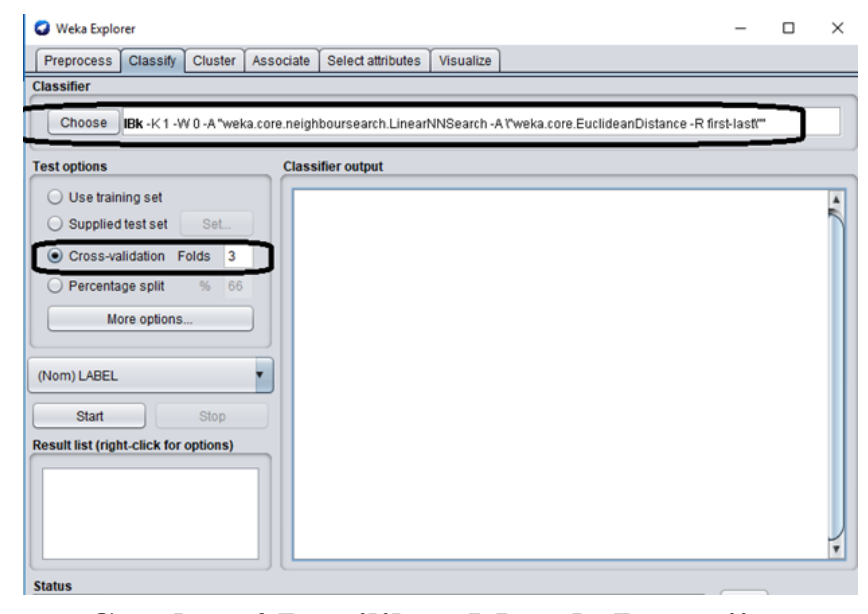

Gambar 4 Pemilihan Metode Pengujian

Setelah semua selesai langkah terakhir adalah menguji data sampling ke-1 dengan meng klik Start dan berikut adalah hasil akurasi data sampling ke-1: 


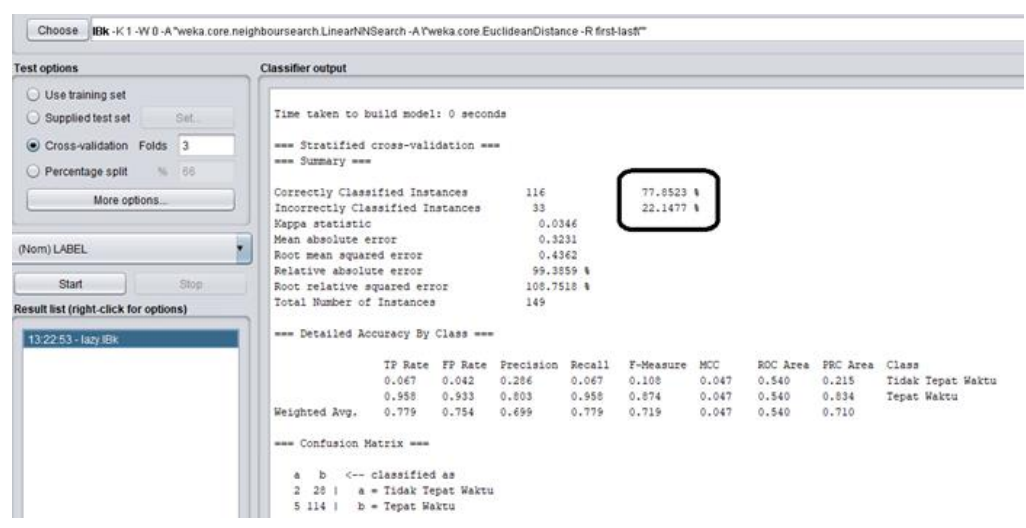

\section{Gambar 5}

\section{Hasil Akurasi Sampling ke-1 Algoritma K-NN menggunakan 3 Fold Cross} Validation

Berikut perhitungan nilai akurasi confusion matrix yang menghasilkan tingkat akurasi sebesar 77,85\% dengan klasifikasi a adalah Tidak Tepat Waktu dan b adalah Tepat Waktu.

1. Pred Tidak Tepat Waktu-true Tidak Tepat Waktu = jumlah data yang diprediksi Tidak Tepat Waktu dan kenyataanya Tidak Tepat Waktu (TP)

2. Pred Tepat Waktu-true Tepat Waktu = jumlah data yang diprediksi Tepat Waktu dan kenyataannya Tepat Waktu (TN)

3. Pred Tidak Tepat Waktu-true Tepat Waktu = jumlah data yang diprediksi Tidak Tepat Waktu tapi kenyataanya Tepat Waktu (FP)

4. Pred Tepat Waktu-true Tidak Tepat Waktu = jumlah data yang diprediksi Tepat Waktu tapi kenyataanya Tidak Tepat Waktu (FN)

$$
\begin{gathered}
\text { Accuracy }=(\mathrm{TP}+\mathrm{TN}) /(\mathrm{TP}+\mathrm{TN}+\mathrm{FP}+\mathrm{FN}) \\
\text { Accuracy }=(2+114) /(2+114+28+5) \\
\text { Accuracy }=116 /(149)=77,85 \%
\end{gathered}
$$

Dari hasil perhitungan dengan rumus dan hasil WEKA menunjukkan bahwa hasil akurasi yang didapatkan adalah sama.

\section{Hasil dan Pembahasan}

Delapan data sampling sudah diujikan dengan langkah-langkah seperti yang sudah dijelaskan sebelumnya. Delapan data sampling diuji dengan 3, 5, 10, 15 dan 20 fold cross validation. Ada alasan yang menjadi dasar pemilihan 3, 5, 10, 15 dan 20 fold cross validation, karena menurut (Witten et al. 2005) 10 fold memberikan hasil prediksi terbaik dalam percobaan dengan beragam data dan beragam algoritma sehingga 10 fold menjadi standar dalam melakukan pengujian tetapi pendapat ini masih sering didebatkan, sehingga peneliti ingin menambahkan 3, 5, 15 dan 20 fold dengan harapan mendapatkan fold yang menghasilkan akurasi terbaik dalam pengujian. Berikut adalah 
Perbandingan Akurasi Software Rapidminer dan Weka Menggunakan Algoritma $K$ Nearest Neighbor (K-NN)

hasil akurasi algoritma K-NN menggunakan tool Rapidminer dan WEKA dengan delapan data sampling menggunakan 3, 5, 10, 15 dan 20 fold cross validation.

Tabel 3

Hasil Pengujian Algoritma K-NN Menggunakan Rapidminer dan WEKA

Hasil Akurasi Algoritma K-NN

\begin{tabular}{|c|c|c|c|}
\hline Sampling & Metode Pengujian Cross Validation & Rapidminer & WEKA \\
\hline 1 & \multirow{8}{*}{  } & $42.20 \%$ & $77.85 \%$ \\
\hline 2 & & $70.50 \%$ & $71.14 \%$ \\
\hline 3 & & $63.06 \%$ & $69.80 \%$ \\
\hline 4 & & $53.62 \%$ & $77.85 \%$ \\
\hline 5 & & $66.44 \%$ & $75.84 \%$ \\
\hline 6 & & $72.54 \%$ & $69.80 \%$ \\
\hline 7 & & $66.45 \%$ & $65.10 \%$ \\
\hline \multirow[t]{2}{*}{8} & & $71.84 \%$ & $75.84 \%$ \\
\hline & Rata - Rata & $63.33 \%$ & $72.90 \%$ \\
\hline 1 & \multirow{8}{*}{5 Fold } & $39.68 \%$ & $76.51 \%$ \\
\hline 2 & & $65.79 \%$ & $73.82 \%$ \\
\hline 3 & & $64.34 \%$ & $76.51 \%$ \\
\hline 4 & & $50.23 \%$ & $75.84 \%$ \\
\hline 5 & & $63.77 \%$ & $71.81 \%$ \\
\hline 6 & & $64.46 \%$ & $72.48 \%$ \\
\hline 7 & & $68.46 \%$ & $63.76 \%$ \\
\hline \multirow[t]{2}{*}{8} & & $69.82 \%$ & $77.18 \%$ \\
\hline & Rata - Rata & $60.82 \%$ & $73.49 \%$ \\
\hline 1 & \multirow{8}{*}{10 Fold } & $32.29 \%$ & $78.52 \%$ \\
\hline 2 & & $67.00 \%$ & $72.49 \%$ \\
\hline 3 & & $63.19 \%$ & $76.51 \%$ \\
\hline 4 & & $43.71 \%$ & $77.18 \%$ \\
\hline 5 & & $62.42 \%$ & $71.81 \%$ \\
\hline 6 & & $67.11 \%$ & $72.48 \%$ \\
\hline 7 & & $67.24 \%$ & $64.43 \%$ \\
\hline \multirow[t]{2}{*}{8} & & $70.48 \%$ & $77.18 \%$ \\
\hline & Rata-Rata & $59.18 \%$ & $73.83 \%$ \\
\hline 1 & \multirow{8}{*}{15 Fold } & $29.48 \%$ & $77.18 \%$ \\
\hline 2 & & $68.59 \%$ & $73.15 \%$ \\
\hline 3 & & $65.11 \%$ & $75.84 \%$ \\
\hline 4 & & $42.81 \%$ & $75.84 \%$ \\
\hline 5 & & $62.52 \%$ & $71.81 \%$ \\
\hline 6 & & $67.33 \%$ & $69.13 \%$ \\
\hline 7 & & $68.52 \%$ & $63.76 \%$ \\
\hline \multirow[t]{2}{*}{8} & & $72.52 \%$ & $77.18 \%$ \\
\hline & Rata-Rata & $59.61 \%$ & $72.99 \%$ \\
\hline 1 & \multirow{8}{*}{20 Fold } & $29.48 \%$ & $78.52 \%$ \\
\hline 2 & & $68.59 \%$ & $72.48 \%$ \\
\hline 3 & & $65.11 \%$ & $77.18 \%$ \\
\hline 4 & & $42.81 \%$ & $77.18 \%$ \\
\hline 5 & & $62.52 \%$ & $73.15 \%$ \\
\hline 6 & & $67.33 \%$ & $72.48 \%$ \\
\hline 7 & & $68.52 \%$ & $65.10 \%$ \\
\hline \multirow[t]{2}{*}{8} & & $72.52 \%$ & $77.85 \%$ \\
\hline & Rata - Rata & $59.61 \%$ & $74.24 \%$ \\
\hline
\end{tabular}




\section{Tabel 4}

Hasil Akurasi Tertinggi

\begin{tabular}{cccccc}
\hline \multicolumn{7}{c}{ HASIL AKURASI TERTINGGI ALGORITMA K-NN } \\
\hline RAPIDMINER & $72,54 \%$ & SAMPLING & 6 & FOLD & 3 \\
\hline WEKA & $78,52 \%$ & SAMPLING & 1 & FOLD & 10,20
\end{tabular}

Dari hasil pengujian algoritma K-NN dengan Rapidminer dan WEKA menggunakan $3,5,10,15$, dan 20 fold cross validation seperti yang telah dijabarkan pada tabel di atas, di dapatkan hasil akurasi tertinggi dengan Rapidminer yaitu sebesar 72,54\% pada data sampling ke-6 dengan menggunakan 3 fold cross validation. Sedangkan pada WEKA, akurasi tertinggi sebesar 78,52\% pada data sampling ke-1 dan ada pada fold ke 10 dan 20 .

\section{Kesimpulan}

Kesimpulan yang diperoleh dari penelitian ini adalah hasil akurasi software WEKA menggunakan algoritma K-NN lebih tinggi yaitu sebesar 78,25\% dibandingkan dengan Rapidminer menggunakan algoritma K-NN yaitu sebesar 72,54\% sehingga software WEKA menggunakan algoritma K-NN dapat menjadi alternatif metode atau metode yang bisa digunakan khususnya pada Universitas Sahid Jakarta dalam memprediksi ketepatan waktu kelulusan mahasiswanya untuk tahun- tahun berikutnya. 
Perbandingan Akurasi Software Rapidminer dan Weka Menggunakan Algoritma $K$ Nearest Neighbor (K-NN)

\section{BIBLIOGRAFI}

Banjarsari, Mutiara Ayu, Irwan Budiman, and Andi Farmadi. 2016. "Penerapan KOptimal Pada Algoritma Knn Untuk Prediksi Kelulusan Tepat Waktu Mahasiswa Program Studi Ilmu Komputer Fmipa Unlam Berdasarkan Ip Sampai Dengan Semester 4.” Klik-Kumpulan Jurnal Ilmu Komputer 2(2): 159-73.Google Scholar

Chertchom, Prajak. 2018. "A Comparison Study between Data Mining Tools over Regression Methods: Recommendation for SMEs." In 2018 5th International Conference on Business and Industrial Research (ICBIR), IEEE, 46-50.Google Scholar

Huda, Nuzulul. 2020. "Klasifikasi Berita Menggunakan Metode Learning Vector Quantization.”Google Scholar

Kamagi, David Hartanto, and Seng Hansun. 2014. "Implementasi Data Mining Dengan Algoritma C4. 5 Untuk Memprediksi Tingkat Kelulusan Mahasiswa.” Ultimatics: Jurnal Teknik Informatika 6(1): 15-20.Google Scholar

Muin, Asrul Ashari. 2016. "Metode Naive Bayes Untuk Prediksi Kelulusan (Studi Kasus: Data Mahasiswa Baru Perguruan Tinggi)." Jurnal Ilmiah Ilmu Komputer Fakultas Ilmu Komputer Universitas Al Asyariah Mandar 2(1): 22-26.Google scholar

Mustafa, Muhammad Syukri, and I Wayan Simpen. 2014. "Perancangan Aplikasi Prediksi Kelulusan Tepat Waktu Bagi Mahasiswa Baru Dengan Teknik Data Mining (Studi Kasus: Data Akademik Mahasiswa STMIK Dipanegara Makassar).” Creative Information Technology Journal 1(4): 270-81.Google Scholar

Mustakim, Mustakim, and Giantika Oktaviani. 2016. "Algoritma K-Nearest Neighbor Classification Sebagai Sistem Prediksi Predikat Prestasi Mahasiswa.” Jurnal Sains, Teknologi dan Industri 13(2): 195-202.Google Scholar

Ngo, Terry. 2011. "Data Mining: Practical Machine Learning Tools and Technique, by Ian h. Witten, Eibe Frank, Mark a. Hell." ACM Sigsoft Software Engineering Notes 36(5): 51-52.Google Scholar

Nursalim, Suprapedi, and H Himawan. 2014. "Klasifikasi Bidang Kerja Lulusan Menggunakan Algoritma K-Nearest Neighbor.” Jurnal Teknologi Informasi 10(1): 31-43. Google Scholar

Rohman, Abdul. 2015. "Model Algoritma K-Nearest Neighbor (K-Nn) Untuk Prediksi Kelulusan Mahasiswa." Neo Teknika 1(1).Google Scholar

Srianto, Didik, and Edy Mulyanto. 2016. "Perbandingan K-Nearest Neighbor Dan Naive Bayes Untuk Klasifikasi Tanah Layak Tanam Pohon Jati." Techno. Com 15(3): 241-45.Google Scholar 
Devi Damayanti

Tinggi, Badan Akreditasi Nasional Perguruan. 2008. "Akreditasi Program Studi Sarjana." Jakarta: BAN PT.Google Scholar

Witten, Ian H et al. 2005. "Kea: Practical Automated Keyphrase Extraction." In Design and Usability of Digital Libraries: Case Studies in the Asia Pacific, IGI global, 129-52Google Scholar.

\section{Copyright holder:}

Devi Damayanti (2021)

First publication right:

Jurnal Syntax Admiration

This article is licensed under:

(c) $\ominus_{\mathrm{BY}} \ominus$ 